\title{
The perceptual properties of electrocutaneous stimulation: Sensory quality, subjective intensity, and intensity-duration relation
}

\author{
TAKARA TASHIRO \\ Osaka City University, Sumiyoshi-ku, Osaka 558, Japan \\ and \\ ATSUKI HIGASHIYAMA \\ University of Osaka Prefecture, Mozu-umemachi, Sakai, Osaka 591, Japan
}

\begin{abstract}
A preliminary and two main experiments designed to examine the perceptual properties of electrocutaneous stimulation are reported. The stimuli used were single short pulses varying in intensity and duration. In Experiment 1, the exponents of power functions fitted to electrocutaneous magnitude estimation data were determined together with the sensory qualities induced by electrical stimulation. The results showed that there was no correlation between the exponent values and the sensory qualities. The mean exponent was 1.2. In Experiment 2, an intensity-duration trading function was constructed from the data obtained from identifying the induced sensory qualities. The results showed that the critical duration increases from 30 to $300 \mathrm{msec}$ with increasing sensation level. These findings are compared with the properties of other sense modalities.
\end{abstract}

The subjective impressions induced by electrical stimulation provide several peculiarities that are not observed in other sense modalities. First, electrical stimulation produces various types of cutaneous qualities, although human skin possesses no specialized receptor sensitive to electrical stimulation. Bishop (1943) showed that when electrical stimulation is delivered at a single sensory spot in the skin surface, the same sensory spot can give a sensation of touch, prick, itch, or sharp pain, depending on the current intensity and repetition rate of stimulus. Furthermore, Ekman, Frankenhaeuser, Levander, and Mellis (1966), Gibson (1968), and Tursky and O'Connell (1972) indicated that, in addition to those cutaneous sensations, an emotional feeling of discomfort or unpleasantness is provided by electrical stimulation.

The second matter of interest is that of subjective intensity produced by electrical stimulation. In many sense modalities, subjective intensity, $\psi$, is related to physical intensity, $\phi$, by a power function (S. S. Stevens, 1961):

$$
\psi=\mathrm{k} \phi^{\mathrm{n}}
$$

We are grateful to Dr. Jiro Kawamura at the Osaka Rosai Hospital and Dr. Kazuyoshi Nishihara at the Osaka Electrocommunication University, who served as advisors on this project. where $\mathrm{k}$ and $\mathrm{n}$ are constants. The value of exponent n depends on sense modality. For electrocutaneous sensation, S. S. Stevens and his co-workers (S. S. Stevens, 1959; S. S. Stevens, Carton, \& Shickman, 1958; J. C. Stevens, Mack, \& S. S. Stevens, 1960), using finger-cup electrodes and $60-\mathrm{Hz}$ sinusoidal current, obtained an exponent of about 3.5. However, these results are not supported by recent studies, except for those of Bujas, Szabo, Kovacic, and Rohacek (1975) and Hawkes (1960). Sternbach and Tursky (1964) replicated S. S. Stevens's experiment in all respects, but the resulting exponent was 1.9 on the average. Babkoff $(1976,1978)$ applied single short pulses to the underside of a wrist and obtained exponents ranging from .9 to 1.4 , depending on the duration of the pulse. On the other hand, Cross, Tursky, and Lodge (1975) and Sachs, Miller, and Grant (1980), using the cross-modality matching technique, obtained exponents of 1.8 to 2.3. These exponents are intermediate between an extremely high value (3.5) and an extremely low value (.9). In any event, there is disagreement concerning the precise value of the exponent.

The third issue of electrocutaneous stimulation concerns temporal integration, which has been studied as the intensity-duration relation necessary to produce any constant level of sensation. The previous evidence presented by Babkoff (1978), Babkoff, Brandeis, and Bergman (1975), Hahn (1958), and 
Rollman (1969) indicated that the hyperbolic function provides a better description of the relation between intensity I-and duration $t$ :

$$
(I-a)(t-b)^{m}=c,
$$

where a, b, c, and $m$ are constants. Hahn (1958) and Rollman (1969) presented evidence that, at absolute threshold, temporal integration is nearly perfect $(m=1)$, while Babkoff (1978) and Babkoff et al. (1975) found that temporal integration is increasingly partial $(m<1)$ as the level of sensation increases from absolute threshold to higher suprathreshold levels.

The intensity-duration relation is available to determine the critical duration for electrical stimulation. The critical duration is defined as the duration beyond which the energy delivered to the receptors cannot be integrated in terms of time. In other words, the critical duration is the minimum value of $t \mathrm{ob}-$ tained when I approaches a (see Equation 2). According to Hahn (1958) and Rollman (1969, 1975), the critical duration was found to be less than $1 \mathrm{msec}$ at absolute threshold. On the other hand, previous studies are not in agreement with respect to the critical duration at suprathreshold levels. Rollman (1975) asserted that the critical duration remains constant regardless of sensation level, while the data of Babkoff (1978) suggests that it is more than $6 \mathrm{msec}$.

Three experiments are reported here: a preliminary and two main experiments. In all the experiments, the electrical stimuli used were single short pulses varying in intensity and duration. All experiments served to describe how the sensory qualities vary as a function of the intensity and duration of the stimulus. In Experiment 1, the exponents of the power functions fitted to the relation between current intensity and subjective intensity were individually determined together with the cutaneous qualities induced by electrical stimulation. Although the previous studies had revealed that the exponents of the power function ranged widely from .9 to 3.5 , it was unclear what the critical variables regulating the variability of the exponents were. Therefore, we thought it would be useful to examine whether or not the variability of the exponents could be accounted for in terms of the cutaneous qualities induced by electrical stimulation. Experiment 2 dealt with temporal integration in relation to the cutaneous qualities. In particular, it was designed to determine whether temporal integration is found throughout the qualities induced by electrical stimulation and whether the critical duration varies depending on the induced sensory qualities.

\section{PRELIMINARY EXPERIMENT AND EXPERIMENT 1}

\section{Method}

Apparatus. A pair of bipolar silver electrodes (Nihonkoden, NE-113S) were constructed to fit into a wooden plate $(1 \times 4 \mathrm{~cm})$ that was strapped to the underside of the right wrist in the vicinity of the ulnar nerve. The diameter of the electrodes was $1 \mathrm{~cm}$; the inner edges of the electrodes were separated laterally by a distance of $2 \mathrm{~cm}$. A constant-current stimulator was used: a dc power supply (Kikusui Electronics Model PAF) was operated at $400 \mathrm{~V}$ and was connected to resistors ranging from .5 to $67 \mathrm{M} \Omega$, accurate to within $1 \%$. Pulse duration and the timing of a trial were controlled by combining a Sanwa time regulator and a Sanwa noncontact relay circuit. Pulse shape and duration were calibrated with a Takeda-Riken Type TR5151 electronics counter in series with a Hitachi Type V-302 oscilloscope. The current was directly measured by a Sanwa Electric Instrument Model 9000 EA digital ammeter.

Procedure. The subject was seated with his/her right hand resting on the table. A woolen mat was spread over the table to keep the hand comfortable. Prior to attachment of the electrodes, the subject's wrist was washed with an alcohol solution. The electrodes were then filled with Nikkoh Kirokushi ECG electrode paste and applied to the underside of the wrist so as to locate the negative electrode close to the palm. A trial was started with the warning sound of a click and followed immediately by a pulse to the electrodes. A stimulus was presented on every trial; no blank trial occurred.

In the preliminary experiment, each subject was presented with 10 stimulus intensities in a random order. The intensities used were: $125,148,185,248,312,385,455,555,652$, and $716 \mu \mathrm{A}$. Stimulus duration was $300 \mathrm{msec}$. All stimuli were presented 15 times to each subject. The intertrial intervals were approximately $10 \mathrm{sec}$.

The task of each subject was to report on the sensory qualities that occurred when each stimulus was presented. In order to perform the experiment promptly and to make the judgments easier, a list of alternatives which contained 10 cutaneous qualities and 2 emotional properties was provided: (A) nothing; (B) a slight touch, as if a breeze were blowing on the wrist; (C) pressure, as if the skin surface were pushed with a stick with a flat end; (D) a prick or sting; (E) deep pressure or heavy blow without pain; (F) deep pressure or heavy blow accompanied by dull pain; (G) deep pressure or heavy blow, but it is difficult to decide whether dull pain occurred; (H) warm; (I) cool; (J) itch; (K) a cold sweat; (L) unpleasant; and (M) other. This list was constructed on the basis of one of the present researchers' own experiences in feeling electrical stimulation and on previous reports on electrocutaneous sensations (Bishop, 1943; Gibson, 1968). The subject was required to choose the alternatives that corresponded most appropriately to the cutaneous or emotional quality that he/she experienced with the stimulation of each pulse.

The subjects were six undergraduates (five males and one female) who had had little experience in psychophysical tasks of electrocutaneous judgments.

In Experiment 1, current intensities presented to the electrodes were: $252,317,390,460,561,659$, and $723 \mu \mathrm{A}$. Stimulus duration was $300 \mathrm{msec}$. The presentation order of stimuli was determined randomly for each subject with each intensity being presented 15 times.

The subjects were required to perform two tasks with the presentation of each stimulus. One task involved magnitude estimation of the apparent intensities of the electrical stimuli. The standard was a $460-\mu \mathrm{A}$ stimulus, approximately the median intensity of the range used, and was assigned the number "10." Each subject was instructed to use the standard as a basis upon which to assign numbers proportional to his/her subjective impression of the intensity of each stimulus. The second task was to identify the sensory qualities induced by the electrical stimulation. An identification list of cutaneous qualities provided to the subjects contained the following alternatives: (I) nothing; (II) slight touch or pressure; (III) prick or sting; (IV) deep pressure; (V) itch or tickle; and (VI) other. On all trials, the subjects made their magnitude estimations before identifying the sensory qualities.

The subjects were 12 undergraduates (seven males and five females). Half of the subjects had served in the preliminary experiment. 
In both the preliminary experiment and Experiment 1 , the choice of the alternatives for sensory qualities was not limited to one for each pulse; the subjects were permitted to choose more than one alternative. Furthermore, when alternative $\mathbf{M}$ or alternative VI was chosen, the subject was required to verbally describe the skin sensation he/she had just perceived. After all judgments had been completed, the experimenter asked the subject whether there were unnecessary alternatives which should be excluded from the original list, or whether there were alternatives which should be added to it.

\section{Results \& Discussion}

Preliminary experiment. The subjects more or less chose all alternatives except for the temperature qualities (alternatives $\mathbf{H}$ and $\mathrm{I}$ ) and the emotional properties (alternatives $\mathbf{K}$ and $\mathbf{L}$ ). The interviews with the subjects suggested that alternative $G$ might as well be combined with alternative $\mathrm{E}$, because it was difficult to draw a clear distinction between the two. Thus, the sensations reported by the subjects could be described in terms of seven cutaneous qualities. When the response frequencies of the seven cutaneous qualities were plotted as a function of current intensity, the peaks of the sensory qualities varied with increasing current intensity in the following sequential order: nothing, touch, pressure, prick, deep pressure, and deep pressure accompanied by dull pain. Furthermore, itch sensation occurred sporadically, independently of current intensity. Some subjects reported that since the sensations classified as itch were stable and unstable, they might be confused with tickle or faint touch.

Experiment 1. Figure 1 shows the overall results obtained from the task of identifying sensory quali- ties: the response frequency of cutaneous qualities is plotted as a function of current intensity. As shown in Figure 1, as current intensity increases, the cutaneous qualities shift from touch or pressure through prick or sting to deep pressure. Also, it is evident that itch sensation occurred with low frequency at every level of intensity, although a slight increase was found at about $300 \mu \mathrm{A}$. These results are generally in agreement with those of the preliminary experiment.

The left portion of Table 1 shows for individual subjects the proportions of response (in percentages) on which each sensory quality occurred. The lines drawn under the proportions represent the quality that was most frequently reported by each subject. Individual differences are notable.

Power functions were fitted to the magnitude estimation data of apparent intensities. For that purpose, geometric means were individually computed on the basis of 15 scores per stimulus. The straight lines were then fitted in log-log coordinates by the method of least squares. The right portion of Table 1 shows the slopes, intercepts, and coefficients of determination $\left(\mathrm{r}^{2}\right)$ of the individual power functions thus fitted.

To test the vitality of the hypothesis that the exponents of the power functions depend on how the electrical stimulation is felt as a cutaneous quality, the 12 subjects were divided into the two subgroups: superficial-sensation group and deep-sensation group. The superficial-sensation group contained Subjects $\mathrm{On}, \mathrm{Ku}, \mathrm{He}, \mathrm{Ko}$, and $\mathrm{Mu}$, whose dominant sensations were touch, pressure, or itch; the deep-sensation group included the remaining subjects, who had indi-

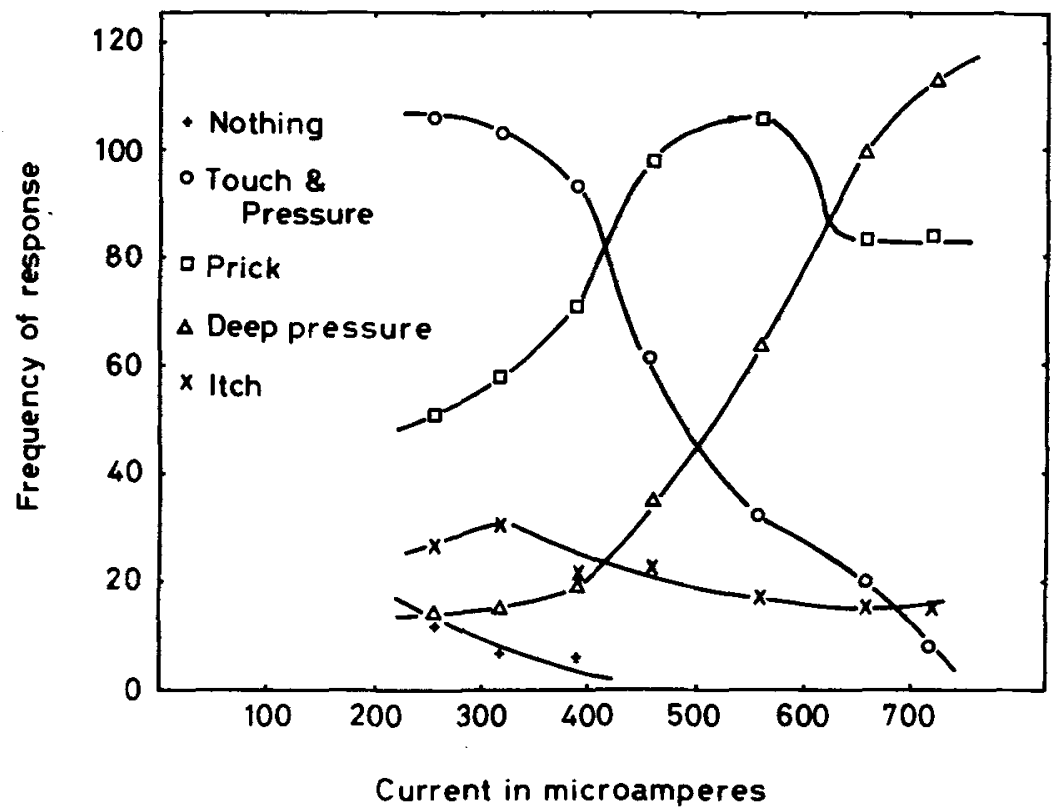

Figure 1. Frequency of response plotted as a function of current intensity in microamperes. The parameter of the curves is sensory quality. 
Table 1

Proportions of Cutaneous Qualities Induced by Electrical Stimulation and Parameters of Power Functions Fitted to the Relation Between Apparent Intensity and Current Intensity

\begin{tabular}{|c|c|c|c|c|c|c|c|c|}
\hline \multirow[b]{2}{*}{ Subject } & \multicolumn{5}{|c|}{ Frequency of Response (in Percentages) } & \multicolumn{3}{|c|}{ Power Function } \\
\hline & Nothing & $\begin{array}{c}\text { Touch and } \\
\text { Pressure }\end{array}$ & Itch & Prick & $\begin{array}{c}\text { Deep } \\
\text { Pressure }\end{array}$ & Slope $\mathrm{n}$ & $\begin{array}{c}\text { Intercept } \\
\log k\end{array}$ & $r^{2}$ \\
\hline On $(\mathrm{m})$ & .0 & 44.7 & 2.9 & 29.5 & 22.9 & 1.316 & -2.560 & .971 \\
\hline $\mathrm{Ku} \mathrm{(m)}$ & 23.8 & 57.1 & .0 & 19.1 & .0 & 3.119 & -7.531 & .994 \\
\hline $\mathrm{He} \quad(f)$ & .0 & 69.8 & .0 & 2.8 & 27.4 & 1.199 & -2.210 & .978 \\
\hline Ko (m) & .0 & $\overline{27.6}$ & 30.5 & 30.5 & 11.4 & .513 & -.395 & .951 \\
\hline $\mathrm{Mu}$ (f) & .0 & 8.8 & 45.6 & $\overline{45.6}$ & .0 & .934 & -1.495 & .940 \\
\hline $\mathrm{Ya}(\mathrm{m})$ & .0 & 28.2 & $\overline{13.4}$ & 34.6 & 23.8 & 1.250 & -2.345 & .995 \\
\hline $\mathrm{Hi} \quad(\mathrm{f})$ & .0 & 31.0 & .0 & $3 \overline{8.9}$ & 30.1 & 1.298 & -2.377 & .893 \\
\hline $\mathrm{Ma}(\mathrm{m})$ & .0 & 31.4 & .0 & 40.0 & 28.6 & .887 & -1.406 & .976 \\
\hline $\mathrm{Be} \quad(\mathrm{m})$ & .0 & 46.7 & .0 & $\overline{53.5}$ & .0 & 1.150 & -2.097 & .937 \\
\hline $\mathrm{Ki} \quad(\mathrm{f})$ & .0 & .0 & .0 & 83.6 & 16.4 & 1.151 & -1.985 & .931 \\
\hline Hir (m) & .0 & 20.5 & .0 & 31.1 & 48.4 & 1.054 & -1.854 & .995 \\
\hline $\mathrm{Si} \quad(f)$ & .0 & .0 & .0 & 20.2 & $\overline{79.8}$ & .816 & -1.103 & .968 \\
\hline
\end{tabular}

cated prick or deep pressure as the dominant sensations. A t test between the two subgroups, however, revealed no significant difference with respect to the exponents $[\mathrm{t}(10)=.869, \mathrm{p}>.05]$. The mean and standard deviation of the exponents taken over the 12 subjects were 1.22 and .66 , respectively.

For the purpose of clarifying the contribution of each sensory quality to the exponent, power functions were fitted for each subject, with sensory quality as a parameter. In making the computations, a geometric mean of magnitude of responses at each current intensity was used as a statistical score. It follows that the geometric means were not necessarily based on an equal number of responses. The results are summarized in Table 2, where the exponents, intercepts, and $r^{2} s$ are averaged across the subjects (N). The results of Table 2 may be characterized by the following: (1) The exponent is smaller than unity for any sensory quality. (2) The exponent at the lower intensities (i.e., touch and pressure) is slightly larger than that at the higher intensities (i.e., prick and deep pressure). (3) Power function may not be best function, because the coefficients of determination are generally low as compared with those of Table 1 . The second and third findings may be similar to the results of Rosner and Goff (1967). They suggested that subjective intensity for electrical stimulation is described by a double-limbed function in log-log coordinates, with a steeper slope (1.8) for the lower inten- sities and a shallower slope (.9) for the higher intensities (cf. Rollman, 1974).

\section{EXPERIMENT 2}

Both the preliminary experiment and Experiment 1 gave evidence that under a constant duration of stimulation, sensory quality systematically varies as a function of current intensity. The purpose of Experiment 2 was to determine the intensity-duration trading function on the basis of the sensory qualities data that were induced by electrical stimuli varying in intensity and duration. In determining the function of temporal integration, it is necessary to establish any constant level of sensation. According to the previous studies, it is customary to use absolute threshold, any fixed value of magnitude estimation, and any fixed value of reaction time as a constant level of sensation. In Experiment 2, instead of those conventional methods, another technique-the method of modality intersection-was used. Figure 1 helps to illustrate the new method. In this graph, there are three main modality curves: touch-and-pressure, prick, and deep-pressure curves. The touch-andpressure curve intersects with the prick and deeppressure curves at about 420 and $510 \mu \mathrm{A}$, respectively, and the prick curve intersects with the deeppressure curve at about $620 \mu \mathrm{A}$. If those intersections

Table 2

Mean Values of Exponent, Intercept, and $\mathbf{r}^{2}$ Computed for Each Sensory Modality

\begin{tabular}{|c|c|c|c|c|c|c|c|c|}
\hline & \multicolumn{2}{|c|}{$\begin{array}{l}\text { Touch and Pressure } \\
(\mathbf{N}=10)\end{array}$} & \multicolumn{2}{|c|}{$\begin{array}{c}\text { Itch } \\
(N=4)\end{array}$} & \multicolumn{2}{|c|}{$\begin{array}{c}\text { Prick } \\
(\mathrm{N}=12) \\
\end{array}$} & \multicolumn{2}{|c|}{$\begin{array}{c}\text { Deep Pressure } \\
(\mathrm{N}=9)\end{array}$} \\
\hline & Mean & SD & Mean & SD & Mean & SD & Mean & SD \\
\hline $\begin{array}{l}\text { Exponent } \\
\text { Intercept } \\
\mathrm{r}^{2}\end{array}$ & $\begin{array}{r}.892 \\
-1.502 \\
.799\end{array}$ & $\begin{array}{r}.633 \\
1.697 \\
.206\end{array}$ & $\begin{array}{l}.133 \\
.482 \\
.528\end{array}$ & $\begin{array}{l}.392 \\
.895 \\
.268\end{array}$ & $\begin{array}{r}.535 \\
-.616 \\
.833\end{array}$ & $\begin{array}{l}.221 \\
.647 \\
.136\end{array}$ & $\begin{array}{r}.763 \\
-.726 \\
.881\end{array}$ & $\begin{array}{r}.377 \\
1.177 \\
.127\end{array}$ \\
\hline
\end{tabular}


of modality curves can be used as constant levels of sensation and they vary as a function of duration, then it will be possible to construct the intensityduration trading function from the task of identifying sensory quality.

\section{Method}

The apparatus was the same as that used in the preliminary experiment. The attachment of the electrodes and the time schedule of a trial were carried over unchanged from the preliminary experiment. Forty-two different stimuli were used: seven levels of current intensity $(247,312,385,455,555,657$, and $717 \mu \mathrm{A})$ at each of six durations $(3,10,30,100,300$, and $600 \mathrm{msec})$, presented in a different random order to each subject. An exposure occurred once every $10 \mathrm{sec}$. All intensity-duration combinations were presented 15 times during two sessions for each subject.

The subject's task was to identify the sensory qualities induced by electrical stimulation. An identification list of cutaneous qualities provided to the subjects contained the following alternatives: (1) nothing; (2) slight touch; (3) pressure; (4) prick or sting; (5) deep pressure; (6) itch or tickle; and (7) other. For a given trial, the subject was required to choose one or more alternatives that represented the cutaneous qualities experienced. When alternative $7 \mathrm{oc}-$ curred, the subject was asked to verbalize what he/she had just experienced in the skin.

The subjects were 12 undergraduates (six males and six females). Nine of the 12 subjects had served in either the preliminary experiment or Experiment 1.

\section{Results and Discussion}

Figure 2 shows the results: The response frequency of sensory qualities that correspond to each of six durations are plotted as a function of current intensity. Figure 2 shows that sensory qualities vary, depending on the intensity and duration of stimulus.
Touch sensation was reported at the lower intensities of less than $400 \mu \mathrm{A}$ and short durations of less than $10 \mathrm{msec}$; deep-pressure responses were reported at the higher intensities of more than $600 \mu \mathrm{A}$ and at the longer durations of more than $300 \mathrm{msec}$; and pressure and prick sensations appeared at moderate intensities and intermediate durations. The frequency of the itch sensation was extremely low at every combination level of intensity and duration.

The current intensity at which modality intersection occurred was determined from any two modality curves in Figure 2. Since the equational forms of the modality curves were unknown, it was decided to compute the intensity corresponding to intersection of two segments on the basis of the four points, two from each curve, that were situated in both sides of the modality intersection.

Figure 3 summarizes the result for all modality intersections except for the combination of itch sensation curve with any other sensation curve. The abscissa stands for duration of stimulus, and the ordinate, for intensity of modality intersection. The parameter is the modality intersection. Figure 3 indicates that, at the lower levels of sensation (e.g., nothing curve vs. pressure curve; nothing curve vs. prick curve), the critical duration was 30 or $100 \mathrm{msec}$, whereas at the higher levels of sensation (e.g., pressure curve vs. deep-pressure curve; touch curve vs. deep-pressure curve), it was $300 \mathrm{msec}$. Furthermore, at the highest level of sensation (i.e., prick curves vs. deep-pressure curve), the current intensities of the modality intersection were nearly constant regardless
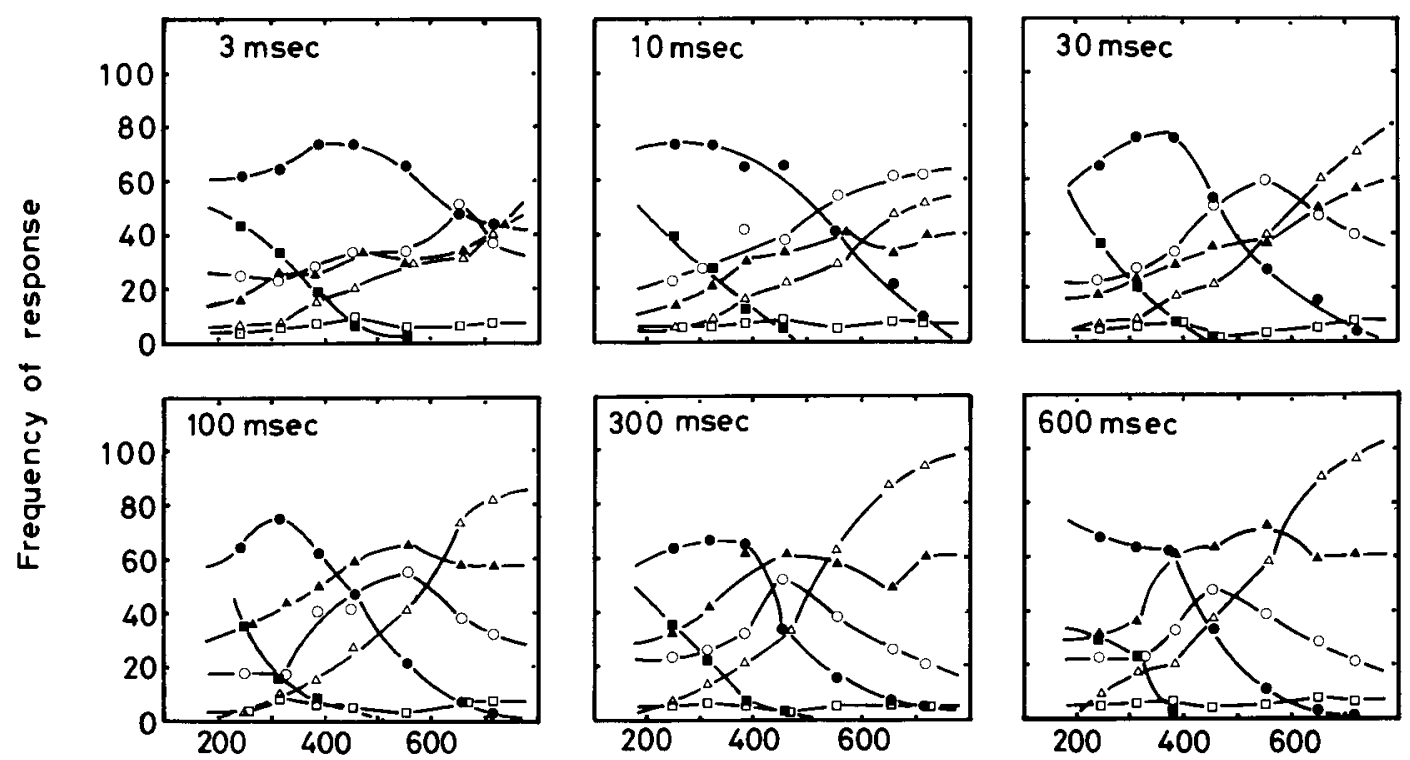

Current in microamperes

Figure 2. Frequency of response plotted as a function of current intensity in microamperes for six durations of stimulus. The parameter is sensory quality: $\square$ nothing; $\bullet$ touch; $O$ pressure; $\Delta$ prick; $\Delta$ deep pressure; $\square$ itch. 


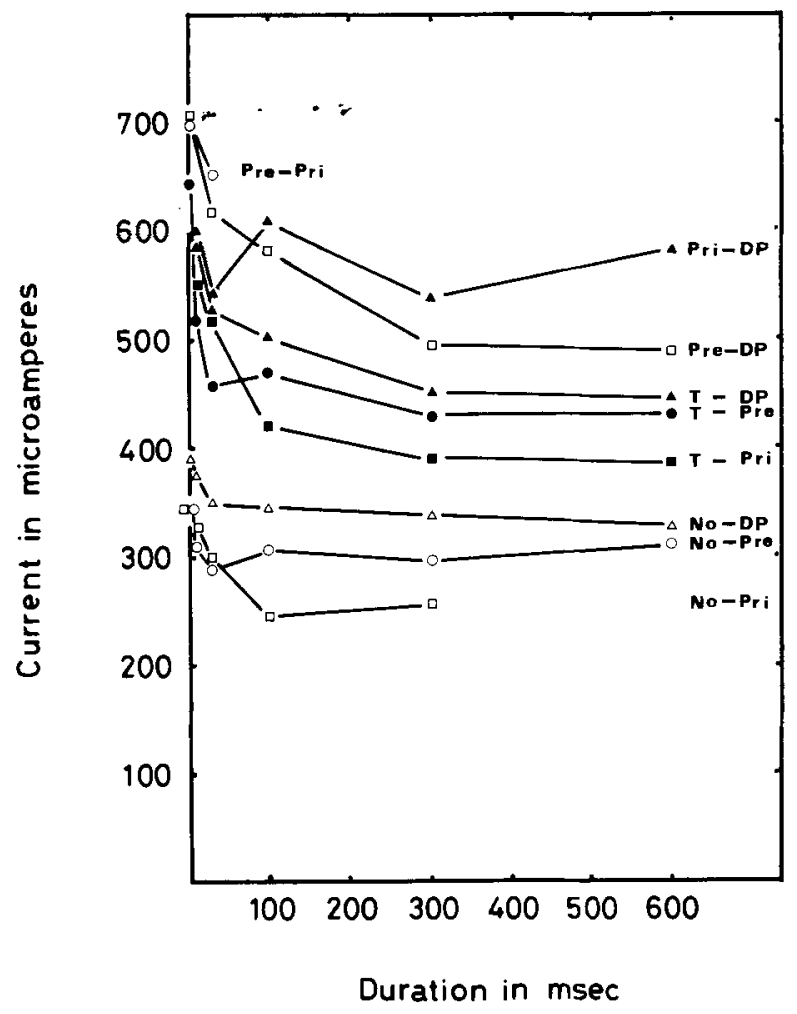

Figure 3. Equal-sensation contours. Current intensity of modality intersection is plotted as a function of duration. The parameter is the level of modality intersection. See text for full explanation. of duration of stimulus. This suggested no temporal integration at that level.

The validity of the method of modality intersection was tested by a somewhat conventional method. Figure 4 is a replotting of Figure 2 as frequency vs. duration, with current intensity and sensory quality as parameters. A two-way analysis of variance with repeated measures was performed for each panel of Figure 4. The results were: The main effect of duration was significant for nothing $[F(5,55)=4.89$, $\mathrm{p}<.01]$, touch $[\mathrm{F}(5,55)=18.03, \mathrm{p}<.01]$, prick $[F(5,55)=10.33, p<.01]$, and deep pressure $[F(5,55)$ $=12.09, \mathrm{p}<.01]$; the main effect of intensity was significant for nothing $[F(6,66)=6.51, p<.01]$, touch $[F(6,66)=11.80, p<.01]$, and deep pressure $[F(6,66)=17.28, p<.01]$; the interaction between duration and intensity was significant for nothing $[\mathrm{F}(30,330)=1.64, \mathrm{p}<.05]$, touch $[\mathrm{F}(30,330)=3.53$, $\mathrm{p}<.01]$, pressure $[\mathrm{F}(30,330)=2.24, \mathrm{p}<.01]$, and deep pressure $[F(30,330)=4.25, p<.01]$. From those results, it is evident that temporal integration occurs at least in the three levels of nothing (absolute threshold), touch, and deep pressure. In addition, it is clear from Figure 4 that the critical duration increases from about 30 to $300 \mathrm{msec}$ with increasing levels of sensation. ${ }^{2}$

\section{GENERAL DISCUSSION}

As shown in Table 1, the power function fitted to the magnitude estimation data accounts for more
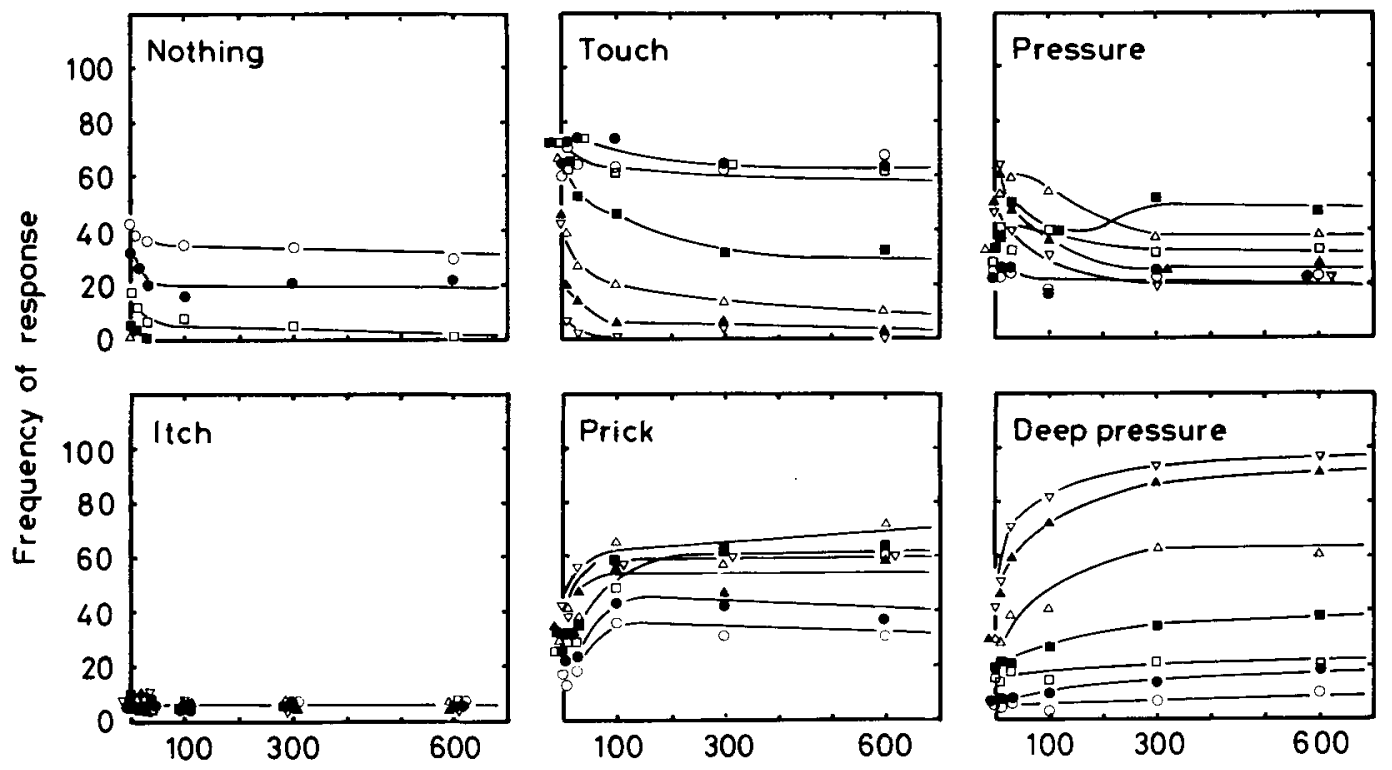

Duration in msec

Figure 4. Equal sensation contours. Frequency of response is plotted as a function of duration. Each panel represents a different modality. The parameter in each panel is current intensity: $\bigcirc 247 \mu \mathrm{A} ; \bullet 312 \mu \mathrm{A} ; \square 385 \mu \mathrm{A}$; $\square 455 \mu \mathrm{A} ; \triangle 555 \mu \mathrm{A} ; \triangle 653 \mu \mathrm{A} ; \nabla 717 \mu \mathrm{A}$. 
than $89 \%$ of the variance in any individual case. This suggests that apparent intensity for electrical stimulation is reasonably described by a power function.

The resulting individual exponents of the power functions ranged from .5 to 3.1 , with an average value of 1.2. The fact that there are considerable individual differences in exponent confirms the finding of Cross et al. (1975), who showed that individual exponents were scattered from 1.65 to 4.08 . The fact that $\mathbf{n}=1.2$ on the average agrees with the studies of Babkoff (1976, 1978), but apparently contradict S. S. Stevens et al. (1958).

The more important result in Experiment 1 is that the variability of the exponents is not related to the sensory qualities reported by the subjects. According to S. S. Stevens (1971), when the skin is stimulated by a $250-\mathrm{Hz}$ vibration, by a $60-\mathrm{Hz}$ vibration, by static pressure, by a decrease in temperature, and by an increase in temperature, the apparent intensities are described by power functions with exponents of .6 , $.95,1.1,1.0$, and 1.5 , respectively. On the other hand, pains produced by radiant thermal stimulation and cold water stimulation grow as power functions with exponents of 1.0 and .65, respectively (Adair, J. C. Stevens, \& Marks, 1968; Hilgard, 1978). In light of those findings, the exponent value of 1.2 obtained for electrical stimulation may reflect the combined effects of different cutaneous qualities, including direct stimulation of the nerves, rather than the isolated effects of any single quality.

The method of modality intersection is available to establish the intensity-duration relation for electrical stimulation. Table 2 and Figure 4 show that temporal integration occurs throughout every level of electrocutaneous qualities. At the same time, they give evidence that the critical duration increases from about 30 to $300 \mathrm{msec}$ as a function of increasing level of sensation.

These results may supplement the study of Babkoff (1978, Figure 4), who showed that at the durations less than $10 \mathrm{msec}$, temporal integration occurs at every level of magnitude estimation. Thus, it is predicted that the critical duration should be more than $10 \mathrm{msec}$ at the suprathreshold levels. The present study is in agreement with this prediction.

On the other hand, Rollman (1975) found that at both absolute threshold and suprathreshold matches to a $1,000-\mathrm{Hz}$ tone at $55-\mathrm{dB}$ sensation level, the threshold current decreased with increasing duration up to about $10 \mathrm{msec}$ and change relatively little beyond that. From this finding, Rollman concluded that the critical duration for electric stimulation remains constant independently of sensation level. The present results are certainly not in agreement with Rollman's conclusion. However, there may be some possibilities to account for that discrepancy. The first explanation is that the intensity-duration function changes depending on the method of determining critical duration. For example, in visual brightness, the critical duration obtained from reaction time is generally shorter than that obtained from such psychophysical measures as response frequency and signal detectability (Bruder \& Kietzman, 1973; Ueno, 1977). Another explanation is that the suprathreshold level provided by Rollman is described as touch sensation rather than pain (prick or deep pressure) sensation. Therefore, if the matching stimulus of a tone is given at the higher level than a 55-dB sensation level, that is, at the level producing prick or deep pressure, then the critical duration may be longer than $10 \mathrm{msec}$. It is unknown which of the two explanations is more plausible.

One usual method used to understand the sensory qualities of electrical stimulation to the skin is to compare them with other sense modalities, for example, to compare warmth and brightness sensations. With respect to the critical duration related to the level of sensation, electrocutaneous data are similar to those for warmth but quite different from those for vision. For the warmth sensation, the critical duration increases from $1 \mathrm{sec}$ to larger durations as the level of magnitude estimation increases (Marks \& J. C. Stevens, 1973). On the other hand, for the brightness sensation, the critical duration decreases from 100 to less than $10 \mathrm{msec}$ as a function of the increasing level of sensation (Grossberg, 1970; Kietzman \& Gillam, 1972; Mansfield, 1973; Raab, 1962; J. C. Stevens \& Hall, 1966; S. S. Stevens, 1966a, 1966b; Ueno, 1977).

With respect to the absolute critical duration, however, electrocutaneous data are similar to visual data, but different from warmth data. Both electrocutaneous and visual data showed that no temporal integration occurs at durations of more than $.5 \mathrm{sec}$ at any level of sensation, while warmth data indicated that temporal integration occurs even at a duration of $10 \mathrm{sec}$ at higher suprathreshold levels (Marks \& J. C. Stevens, 1973).

The method of modality intersection may be applied not only to electrocutaneous sensations, but other sense modalities as well. Clark (1969), Dillon (1971), Fujita (1930), and Lele, Weddell, and Williams (1954) showed that radiant thermal stimulation to the skin produces the sensations of warmth, sting, pain, itch, and occasionally faint touch, depending on the intensity and duration of heat transfer. A similar transition of sensory qualities was found by Guilford and Lovewell (1936) and Yai (1959, 1961) for mechanical stimulation of the skin. Therefore, the method of modality intersection appears to be a very promising technique for analyzing the intensityduration relation of these cutaneous qualities.

\section{REFERENCES}

Adair, E. R., Stevens, J. C., \& Marks, L. E. Thermally induced pain, the dol scale, and the psychophysical power law. American Journal of Psychology, 1968, 81, 147-164. 
BAвkoff, H. Magnitude estimation of short electrocutaneous pulses. Psychological Research, 1976, 39, 39-49.

BABKOFF, H. Electrocutaneous psychophysical input-output functions and temportal integration. Perception \& Psychophysics, 1978, 23, 251-257.

Babkoff, H., Brandeis, B., \& Bergman, Y. Partial integration of single electrocutaneous pulses. Perception \& Psychophysics, $1975,17,285-292$.

Bishop, G. H. Responses to electrical stimulation of single sensory units of skin. Journal of Neurophysiology, 1943, 6, 361-382.

Bruder, G. E., \& Kietzman, M. L. Visual temporal integration for threshold, signal detectability, and reaction time measures. Perception \& Psychophysics, 1973, 13, 293-300.

Bujas, Z., Szabo, S., Kovacic, M., \& Rohacek, A. Sensory scales for electrical stimuli in three sense modalities. Acta Instituti Psychologici, University of Zagreb, 1975, 75, 17-23.

Crark, W. C. Sensory-decision theory analysis of the placebo effect on the criterion for pain and thermal sensitivity (d'). Journal of Abnormal Psychology, 1969, 74, 363-371.

Clark, W. C., \& Yang, J. C. Acupunctural analgesia? Evaluation by signal detection theory. Science, 1974, 184, 1096-1098.

Cross, D. V., Tursky, B., \& Lodge, M. The role of regression and range effects in determination of the power function for electrical shock. Perception \& Psychophysics, 1975, 18, 9-14.

Dillon, D. J. Temporal summation of pain from radiant stimulation. Perception \& Psychophysics, 1971, 10, 109-111.

Ekman, G., Frankenhaeuser, M., Levander, S., \& Meluis, I. The influence of intensity and duration of electrical stimulation on subjective variables. Scandinavian Journal of Psychology, $1966,7,58-64$.

FujitA, T. [Cutaneous experiences induced by thermal stimulation: Heating pain and heating itch.] Japanese Journal of Psychology, 1930, 5, 549-581. (In Japanese)

Gibson, R. H. Electrical stimulation of pain and touch. In D. R. Kenshalo (Ed.), The skin senses. Springfield, Ill: Thomas, 1968.

Grossberg, M. Frequencies and latencies in detecting two-flash stimuli. Perception \& Psychophysics, 1970, 7, 377-380.

Guilfond, J. P., \& Lovewell, E. M. The touch spots and the intensity of the stimulus. Journal of General Psychology, 1936, 15, 149-159.

HahN, J. F. Cutaneous vibratory thresholds for square-wave electrical pulses. Science, 1958, 127, 879-880.

HAwkEs, G. R. An evaluation of the magnitude estimation technique. Journal of Psychology, 1960, 50, 303-313.

HiloaRd, E. R. Pain perception in man. In R. Held, H. W. Leibowitz, \& H. L. Teuber (Eds.), Handbook of sensory physiology (Vol. 8). Berlin: Springer-Verlag, 1978.

Kietzman, M. L., \& Gillam, B. J. Visual temporal integration and simple reaction time. Perception \& Psychophysics, 1972, 11, 333-340.

Lele, P. P., Weddell, G., \& Williams, C. M. The relationship between heat transfer, skin temperature and cutaneous sensitivity. Journal of Physiology, 1954, 126, 206-234.

Mansfield, R. J. W. Latency functions in human vision. Vision Research, 1973, 13, 2219-2234.

Marks, L. E., \& Stevens, J. C. Temporal summation related to the nature of the proximal stimulus for the warmth sense. Perception \& Psychophysics, 1973, 14, 570-576.

$R_{A A B}, D$. Magnitude estimation of the brightness of brief foveal stimuli. Science, 1962, 135, 42-43.

Rollman, G. B. Electrocutaneous stimulation: Psychometric functions and temporal integration. Perception \& Psychophysics, $1969,5,289-293$.

Rollman, G. B. Electrocutaneous stimulation. In F. A. Geldard (Ed.), Cutaneous communications systems and devices. Austin, Tex: Psychonomic Society, 1974.

Roliman, G. B. Behavioral assessment of peripheral nerve function. Neurology, 1975, 25, 339-342.

Rosner, B. S., \& GoFF, W. R. Electrical responses of the nervous system and subjective scales of intensity. In W. D. Neff (Ed.), Contribution to sensory physiology (Vol. 2). New York: Academic Press, 1967.

Sachs, R. M., Miller, J. D., \& Grant, K. W. Perceived magnitude of multiple electrocutaneous pulses. Perception \& Psychophysics, 1980, 28, 255-262.

Sternbach, R. A., \& Tursky, B. On the psychophysical power function in electric shock. Psychonomic Science, 1964, 1, 217-218.

Stevens, J. C., \& Hall, J. W. Brightness and loudness as functions of stimulus duration. Perception \& Psychophysics, 1966, 1, 319-327.

Stevens, J. C., Mack, J. D., \& Stevens, S. S. Growth of sensation on seven continua as measured by force of handgrip. Journal of Experimental Psychology, 1960, 59, 60-67.

Stevens, S. S. Cross-modality validation of subjective scales for loudness, vibration, and electric shock. Journal of Experimental Psychology, 1959, 57, 201-209.

Stevens, S. S. Matching functions between loudness and ten other continua. Perception \& Psychophysics, 1966, 1, 5-8. (a)

Stevens, S. S. Duration, luminance, and the brightness exponent. Perception \& Psychophysics, 1966, 1, 96-100. (b)

Stevens, S. S. Sensory power functions and neural events. In W. R. Loewenstein (Ed.), Handbook of sensory physiology (Vol. 1). Berlin: Springer-Verlag, 1971.

Stevens, S. S., Carton, A. S., \& Shickman, G. M. A scale of apparent intensity of electric shock. Journal of Experimental Psychology, 1958, 56, 328-334.

Tursky, B., \& O'Connell, D. Reliability and interjudgment predictability of subjective judgments of electrocutaneous stimulation. Psychophysiology, 1972, 9, 290-295.

UENo, T. Reaction time as a measure of temporal summation at suprathreshold levels. Vision Research, 1977, 17, 227-232.

$Y_{A I}, H$. [The effects of side-pressure on pressure sensation.] Japanese Journal of Psychology, 1959, 29, 9-18. (In Japanese)

YAI, H. Studies on pressure spots (1). Japanese Psychological Research, 1961, 3, 57-70.

\section{NOTES}

1. Assigning number " 10 " as a modulus seems to have made the subject's task easier, because electrical stimulation is unstable and subtle at lower intensities.

2. One might argued that the data of Experiment 2 can be analyzed by the theory of signal detection. In fact, Clark (1969) and Clark and Yang (1974) applied the theory of signal detection to temperature sensation and succeeded in separating thermal sensitivity ( $\left.d^{\prime}\right)$ from response bias. However, since no blank trial was included in Experiment 2, it does not seem appropriate to use the theory in the original form.

(Manuscript received April 14, 1981; revision accepted for publication August 15, 1981.) 